\title{
Research on Cultivation Model Reform of Technical and Skilled Talents of Logistics Management of Higher Vocational Colleges
}

\author{
Fengyu Wei, Mingming Li, Qi Zeng, Jianguo Ma, Jing Dong \\ Chongqing College of Finance and Economics, Chongqing, 402160, \\ China
}

\begin{abstract}
In order to develop the higher vocational education with high-quality technical talents and meet the demand of the current logistics management specialty, the higher vocational colleges have combined the situation with the modern apprenticeship reform thoughtandachieved some success. Guided by the modern apprenticeship, our professional logistics management team conducted the reform of "Three Layers Intersection". This paper introduces the exploration and implementation of the reform, analyzes the problems found in the reform, and puts forward the follow-up direction of the reform in order to find problems, exchange experiences, and promote the smooth implementation of the reform.

Keywords:logistics management, modern apprenticeship, talent cultivation model, college-enterprise cooperation
\end{abstract}

\section{Exploration of talents cultivation model}

The logistics personnel can be divided into three layersin the whole logistics industry: engaged in the actual operation of the operation layer, engage in specific logistics operation management, as well as in the overall strategic planning of enterprise senior management, decision-making. As a higher vocational college, we cultivate the technical skills of the compound talents, which refer to the talent level for targeted training.

Training objectives of logistics management specialty in higher vocational schools should be the foothold of grass-roots management positions, students in mastering the basic theory knowledge and skills on the line. We should 
strengthen the basic management courses and management training. Therefore, the logistics management professionals in the latter part of the training should be gradually added to various types of management courses to ensure that students can be engaged in the management of the basic needs of professional quality. At the same time, according to the different types of the needs of enterprises, combined with the students with different direction and to expand the curriculum strong, focus on the cultivation of students' thinking and pattern of consciousness, and strive to make enterprises in the high-level knowledge, thought and ability reserve for later.

Based on the above reasons, we have carried out a bold reform of logistics management specialty. From the enterprise actual situation, introduced the concept of virtual enterprises in the process of teaching, the students of different grades in cross grouping construction company, with three levels of students to adapt to the company's operations in the operation layer, management layer and decision layer in different positions of the occupation skill as the goal, to guide students to participate in the competition, stimulate students' interest in learning the supply and demand of logistics management professionals to achieve a balance.

\section{Reform implementation of talents cultivation model}

\subsection{Strengthened practical teaching sections}

In order to obtain employment and students into the school, school to meet the needs of enterprises and personnel training, and whether graduates meet the business requirements, to evaluate the quality of personnel training in key schools. Based on this, we have deep cooperation as a key work in specialty construction, to the modern apprenticeship as guiding ideology. The school teacher professor of professional knowledge, job skills training enterprise backbone teaching methods, achieve enterprise implanted depth cooperation, reflects the integration of education and occupation, from students to help students realize the apprentice to the staff role change.

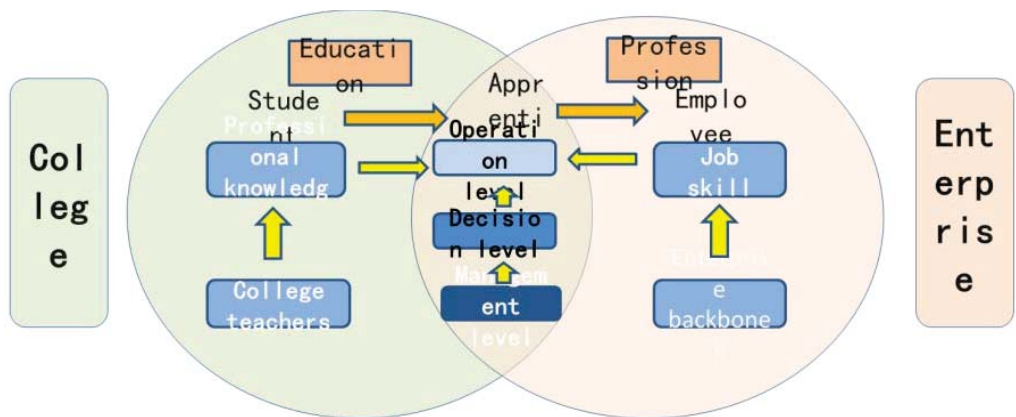

Figure 1. Deep collaborative cultivation of colleges and enterprises 


\subsection{Practice of "Three Layers Intersection"}

From the proposed idea to the formation of the team, and then to the implementation of the design, our school has been the three layers of integration of the reform of the idea to apply to the school in the three grades of personnel training programs. When the construction of curriculum system, using the " $2+3+7 "$ mode, namely professional basis platform and professional core platform two platform, operation management level and decision level three module, warehousing operation, transportation, marketing and customer service, and cost, logistics and logistics, supply chain management, organization management seven a training package. Also, the training management of logistics enterprises throughout the simulation table, the sand table training task learning all courses series, "learning" to "enhance training, plus each semester has the opportunity to logistics enterprise practical training, the enterprise really play" the apprentice "role.

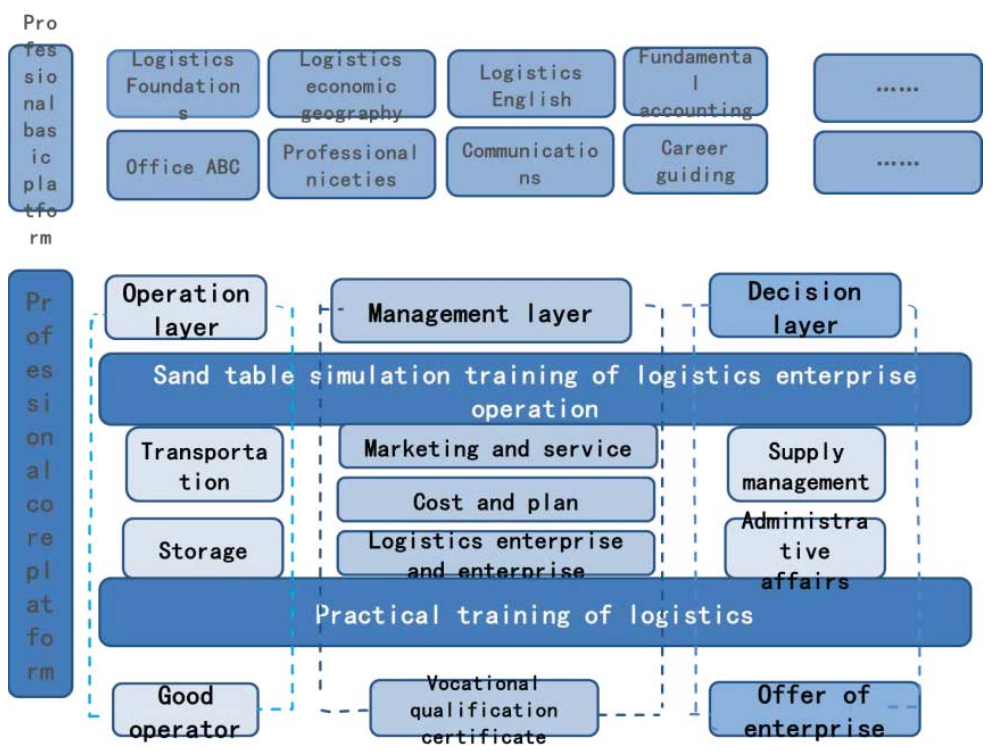

Figure 2. Curriculum system of "Three Layers Intersection"

\section{Problems and Countermeasures in reform practice}

\subsection{Improve practical conditons}

Our school has built a training simulation training room, warehousing and distribution logistics information systems, forklift, forklift trucks, manual hydraulic pallet trucks, automatic warehouse, heavy shelves, shelves and in various types of tray, turnover box and cardboard boxes and other facilities, but the operation of virtual enterprise training by location restrictions. The real 
simulation of the logistics business office site is easy to operate virtual enterprise activities.

\subsection{Increase cooperative enterprises}

Currently the training plan formulation and implementation of the logistics enterprises in our school personnel, warehousing and distribution enterprises, considering the professional characteristics and the actual needs of students' employment, we also need to develop transportation, integrated logistics enterprise resources, in the enterprise business as far as possible to completely cover. In addition, the degree of participation in the development of training courses and personnel training programs should also be deepened, in order to better achieve the natural transition between the enterprise and the employees in the enterprise.

\subsection{Set Management Content}

At present, our students in the internship is a chance to participate in the competition, but the competition for success and can contact the management business only a minority, so more management training content can only be arranged in simulation training. After the stage we will be linked with the enterprise, in the grassroots management positions to arrange more training projects, the management of the training of students from the school simulation gradually transferred to the real scene.

\subsection{Construct stimulation policies}

In training students will bring students emotional dissatisfaction. If the piece rate pay part of the business enterprise, digestion of our students, which will lead to enterprise employee dissatisfaction. Therefore, in the depth of cooperation in the development of enterprises, we need to establish and improve the incentive policy, the development of both the incentive to school students, but also does not affect the policy of employees.

\section{Achievements of reforms}

Because of breaking the disciplinary boundaries, the original teaching materials have not been able to adapt to the new teaching model of the profession, so the professional start all teachers, school-based teaching materials in order to meet the needs of the new model of teaching. In the process of reform, I developed a new team of cooperative enterprises; deepen the depth of the original enterprise cooperation, opened up a new model of school enterprise cooperation. The reform of the students after graduation internship, employment and training are put into the second phase of the completion of the second phase is conducive to improving the recognition of the students of the enterprise. After this mode of training students, most of them can find suitable for their own development in the school enterprise cooperation. 


\section{Conclusion}

From the discovery of school education and the needs of the enterprise, to reset the personnel training objectives and positioning; from the adjustment of the structure of personnel training, to optimize the curriculum system; from the initial reform difficult, the teachers and students to fully adapt to the new pattern. Since the implementation of the reform, has made some achievements, but also encountered many difficulties. The feedback from the students and enterprises, correct and means is the direction of our reform is effective, will further improve the training conditions, reinforce teachers, deepen cooperation, to cultivate more high quality to adapt to the technical skills of logistics professional people to continue to need continuous exploration.

\section{Acknowledgement}

This research is the result of the "Key Project of Teaching Reform Research of Chongqing Higher Education" (Grant No. 142081). The project name is "Research and Practice of Talent Cultivation Model and Curriculum System Constructionof 'Three Layers Intersection' of Logistics Management Major in the Condition of Enterprise Operation".

\section{References}

[1]Huang Qifa, Huang Jiahui, Investigation of Compound Logistics Managers andOptimization for Training Mode, Marketing Management Review, 11(9), pp. 102-103, 2015.

[2]Li Mingming, Wei Fengyu, Zeng Qi, Ma Jianguo, Dong Jing, Searching on the Cultivating pattern of Logistics in Higher vocationalcolleges under the age of Big data, Logistics Engineering and Management, 37(3), pp. 248-249+236, 2015.

[3]Wang Shunlin, Chen Yifang, Under the Background of Internet+, the Analysis of Constraint Factors and Technical Skill Requirements about Higher Vocational Logistics Information Talent Cultivation, LogisticsSci-Tech, 39(5), pp. 51-53, 2015.

[4] Zhou Lu, Deng Peilin, Study on "123” Innovative Talent Cultivation Mode of Higher Vocational Logistics Management Specialty, Logistics Technology, 34(2), pp. 313-315, 2015. 